\author{
Iván Muñoz Ovalle* \\ Carlos Choque Mariño**
}

\author{
INTERACCIÓN Y CAMBIO SOCIAL: UN RELATO ARQUEOLÓGICO E \\ HISTÓRICO SOBRE LAS POBLACIONES QUE HABITARON \\ LOS VALLES PRECORDILLERANOS DE ARICA DURANTE \\ LOS SIGLOS X AL XVII D. C $\mathrm{C}^{* * *}$
}

\begin{abstract}
RESUMEN
En la precordillera de Arica, norte de Chile, interactuaron durante los siglos $\mathrm{X}$ al XVII dos grandes tradiciones culturales, la primera con origen en los valles occidentales, conocida arqueológicamente como Cultura Arica, y la segunda de origen altiplánico, vinculada a los Reinos Aimaras Postiwanaku, específicamente Carangas. A través del estudio de su arquitectura y cerámica, hemos podido definir el entretejido cultural que ambas tradiciones forjaron. El éxito socioeconómico alcanzado por estas poblaciones fue la base sobre la cual se asentó, con estrategias de dominio diferenciadas, primero el Inca y posteriormente el Europeo. El presente trabajo propone una síntesis de esta compleja historia, haciendo hincapié en los cambios sociales y culturales ocurridos en los valles altos de Arica. Para alcanzar este objetivo nos hemos nutrido tanto de las herramientas metodológicas que pone a nuestra disposición la arqueología y la historia, como de las investigaciones que se han desarrollado con intensidad los últimos 30 años.
\end{abstract}

Palabras clave: etnicidad, precordillera de Arica, población indígena, historia colonial.

\title{
ABSTRACT
}

In the Arican foothills north of Chile two important cultural traditions interacted from the tenth to the seventeenth century. The first tradition originated in the western valleys and is known archeologically as Arica Culture. The second, originated in the Chilean Altiplano, was related to the Aimara and the Postiwanaku kingdoms, specifically Carangas. Through the study of their architecture and ceramics, we have been able to define the cultural connections that both traditions forged between them. The socio economic success reached by these cultures was the base used by the Incas

* Doctor en Antropología, Universidad Nacional Autónoma de México. Académico en el Departamento de Antropología, Facultad de Ciencias Sociales y Jurídicas, Universidad de Tarapacá. Arica-Chile. imunoz@uta.cl

** Doctor en Antropología en Pontificia Universidad Católica del Perú. Académico en el Departamento de Ciencias Históricas y Geográficas, Facultad de Educación y Humanidades, Universidad de Tarapacá. Arica-Chile cochoquem@uta.cl

*** Este artículo es producto de los proyectos Fondecyt No 1130249 - 11130024 y del Convenio de Desempeño UTA-Mineduc. 
first and later by the Europeans to settle in the region, although they utilized different strategies of control. The article proposes a synthesis of this complex history, highlighting the social and cultural changes that occur in the high valleys of Arica. To realize this objective we have utilized historical and archeological methodologies as well as research that has been intensively developed within the last thirty years.

Key Words: ethnicity, Arican foothills, Indigenous population, colonial history.

Fecha de recepción: abril de 2013.

Fecha de aceptación: noviembre de 2013.

\section{El ESPACiO}

El desierto de Atacama, norte de Chile, se caracteriza por presentar condiciones hostiles para el desarrollo humano, no obstante, el contexto de extrema aridez que presenta, es posible encontrar áreas con rasgos especiales que han permitido la existencia de asentamientos humanos de tipo permanente. Estas poblaciones han intervenido el medio ambiente árido, con creatividad y esfuerzo, modificándolo y adaptándolo a sus necesidades. Entre los sectores que resaltan por su especial naturaleza encontramos la precordillera. Esta entidad geográfica se compone de una sucesión de relieves, que avanzan desde el litoral hacia el este, aumentando en altitud y con una clara disposición norte-sur. Se caracteriza por la existencia de condiciones naturales de menor hostilidad que el que se encuentra al oriente, en el altiplano, y al occidente, en la pampa. En el caso del extremo norte de Chile, este espacio geográfico conocido también como sierra, cumple un importante papel articulador, entre las tierras altoandinas, correspondientes al altiplano y las tierras bajas del Pacífico, conformadas por los valles costeros y el litoral. Siendo un territorio de transición entre estos dos espacios de características ambientales manifiestamente distintas, ha favorecido las comunicaciones e intercambios entre poblaciones en el sentido este-oeste.

En este paisaje natural, donde se hallan las cabeceras de valle, topográficamente quebrado e irregular, pedregoso, árido y con condiciones térmicas restrictivas para la agricultura, las poblaciones prehispánicas se constituyeron en agentes transformadores del medio, dando origen, al igual que en otros sectores montañosos de los Andes, a los sistemas de terrazas de cultivos o andenerías, gracias los cuales fue posible maximizar los suelos cultivables y extender las fronteras agrícolas de los altos de Arica. Este espacio fue fundamental para el cultivo de determinadas especies de maíz y papas, recursos fundamentales para el mantenimiento de los agricultores precordilleranos.

\section{La Cultura Arica, inicios del poblamiento a través de yungas y PeSCADores}

La precordillera del extremo norte de Chile, si bien fue poblada hace 11.000 años por bandas forrajeras, denota una ausencia generalizada de asentamientos en los períodos posteriores, a saber período Formativo y Medio (500 a.C- 900 d.C.). Sin em- 
bargo a partir del fin del Período Medio, caracterizado por la influencia de Tiwanaku e inicios del Intermedio Tardío (950 d.C.), observamos un aumento demográfico importante, manifestado en el surgimiento de una gran cantidad de poblados enclavados principalmente en las laderas de valles y cimas de los cerros. Esta situación no fue espontánea sino que responde a un proceso gradual de ocupación del espacio, manejado desde la costa hacia las cabeceras de valles, sierra y faldeos de la cordillera andina ${ }^{1}$.

Estos poblados fueron construidos en base a recintos de forma circular, con muros de piedras tanto simples y como dobles. En el interior se encontraron diversas áreas de actividad, la mayoría vinculadas a la preparación y consumo de alimentos, y para pernoctar. Sin embargo, se ha constatado que gran parte de la actividad cotidiana se desarrolló en la "chacra", en el área dedicada al cuidado de animales y en los sectores públicos como plazas y espacios ceremoniales, donde interactuaron como comunidad agraria ${ }^{2}$. Desde el punto de vista funerario, enterraron a sus muertos en tumbas subterráneas, algunas recubiertas con piedras y con lajas en su superficie. Tanto las habitaciones como pozos de almacenajes y cementerios están estrechamente relacionados con un entramado de senderos o pasillos centrales, los que corresponderían a la columna vertebral de los poblados. A partir de ello se planificó el asentamiento con pasillos secundarios, a veces escalonados según la topografía donde fueron levantados los recintos. Otras áreas relevantes de carácter económico en la organización de los poblados tiene relación con extensas terrazas y canales de regadío y grandes recintos donde albergaron camélidos (corrales), ambos espacios constituyeron la base económica de los antiguos pobladores de la Cultura Arica.

Desde el punto de vista de sus bienes, destaca su alfarería, con formas de ollas, jarras y coquitos, estas fueron pintadas y decoradas de distintos colores, siendo posible reconocer tres estilos (San Miguel, Pocoma y Gentilar). Fueron hábiles tejedores, evidencia que se constata la presencia de artefactos de tejeduría como torteros, vichuñas, lana, agujas halladas tanto en los recintos habitacionales como ofrendas depositadas a sus muertos en cementerios. En el trabajo de la piedra, confeccionaron diferentes artefactos como puntas de forma lanceoladas, pedunculadas, raspadores, punzones, instrumentos de labranzas como terrones y picos ${ }^{3}$.

El modelo de ocupación de la Cultura Arica estuvo dado a partir de la existencia de recursos hídricos permanentes, sumado a la creación de redes viales (senderos), lo que permitió el establecimiento de un sistema de comunicación eficaz entre los distintos asentamientos emplazados en distintas quebradas de la sierra de Arica. Esto ayudó a superar los momentos de tensión y conflictos producidos con otros grupos, por el control de los recursos hídricos y el espacio territorial.

1 Iván Muñoz y Juan Chacama, Complejidad Social en las Alturas de Arica: Territorio, Etnicidad y vinculación con el Estado Inca, Arica, Universidad de Tarapacá, 2006. Álvaro Romero, Organización Social y Económica Política en la Prehistoria Tardía de los valles de Arica (1100-1530), Memoria para optar al título profesional de arqueólogo, Universidad de Chile, Santiago, 2005.

2 Iván Muñoz, "Ocupación del espacio doméstico y áreas de actividad generadas en el asentamiento prehispánico de San Lorenzo", Diálogo Andino 24, Arica, 2005, 53-98.

3 Iván Muñoz, "Organización del espacio doméstico y áreas de actividad en un asentamiento prehispánico de altura, período Intermedio Tardío, norte de Chile”, Chungará 39:2, Arica, 2007, 259-284. 
Las evidencias arqueológicas señalan que estas poblaciones habrían estado organizadas políticamente en pequeños cacicazgos, los que manejaban territorios en los valles costeros y serranos. Poblados como Copaquilla, Chapicollo, Huaycuta, Calacruz, Caillama, Huaihuarani, Lupica, Belén, etc., entre otros, serían testimonios de estas aldeas circunscritas a estos cacicazgos.

Ahora bien, los estudios etnohistóricos desarrollados por Rostworowski señalan que antes de la administración Inca, existió un espacio territorial conocido como "Colesuyo"4, el cual se extendió desde Camaná hasta el valle de Tarapacá en la vertiente occidental andina 5 . Este espacio era habitado por varios curacazgos conformados por poblaciones "yungas" compuestas por agricultores llamados "Coles" y pescadores denominados "Camanchacas" o "Cavanchas" Cerron-Palominos", habrían utilizado por lengua el "Coli", que fue una variante local del "puquina". Ambos grupos si bien vivían separados, intercambiaban sus productos y el poder lo ejercía el cacique principal que vivía en los valles ${ }^{10}$.

A pesar de haber conformado pequeños cacicazgos, encontramos en los valles costeros una rica iconografía en la cerámica y especialmente en los textiles, la que destaca por sus variados diseños y colores. Estos objetos habrían constituido verdaderos emblemas de identidad, remarcando sus orígenes y sus vínculos con la territorialidad y los ancestros ${ }^{11}$. La generación de la "identidad" permitió el aglutinamiento e inclusión de las antiguas formas de ser de las sociedades costeras, sus memorias de origen y las representaciones simbólicas individuales y colectivas. Además, sus construcciones fueron múltiples, ya sea por medio de los discursos, prácticas, experiencias y posiciones diferentes, no siendo además unificadas, sino más bien fragmentadas y fracturadas, como señalo Stuard Hall' ${ }^{12}$, dando paso a diversas representaciones

\footnotetext{
4 María Rostworowski, "La región del Colesuyo”, Chungará 16-17, Arica, 1986, 127-136.

5 Katherine Julien, "Koli: A language spoken on the Peruvian Coast", Andean Perspective Newsletter 3, Austin, Austin University, 1979, 45-65.

6 Se cree que el vocablo yunga o yunca tiene su origen en el quechua y significaba "valle cálido". La administración colonial utilizó este concepto para designar e identificar a los indios de las tierras bajas del Perú.

7 Alfredo Torero, Lingüística e Historia de la sociedad andina, Científicos de la Universidad Nacional Agraria, Vol. VIII, números 3-4, Lima, 1970.

8 Therese Bouysee-Cassagne, "Le lac Titicaca: histoireperdue d' une merintérieure", Bulletin de l'Inst itutfrancaisd'EtudesAndines 21:1 12 , Lima, 1992, 89-159.

9 Rodolfo Cerrón Palominos, Voces del Ande. Ensayos sobre Onomástica Andina, Lima, Editorial PUCP, 2008.

${ }^{10}$ Al respecto, Julien nos dice que los "yungas" no solo vivieron en el litoral o valles costeros, sino que también en zonas como Tarata al interior de Tacna y en la precordillera de Moquegua, en los distritos de Carumas y Ubinas. Julien, op. cit., 52. En este contexto de ocupación del espacio, la población yunga también se ubicó en zonas como Socoroma, Putre, Belén, Tignamar o Codpa como lo demuestran las evidencias arqueológicas de tradición costera localizadas en esta zona.

${ }^{11}$ Carlos Choque y Elías Pizarro, "El Colesuyu meridional: Espacio de articulación económica y cultural hispano-indígena en el siglo XVI", Allpanchis volumen 73-74, Cusco, Instituto Pastoral andina, 2012, 241-268.

12 Stuard Hall, "Cultural identity and diaspora", J. Rutherford (Ed.), Identity: Community, Culture, Difference, London, Lawrence \& Wishart, 1990, 222-237.
} 
de la historia, la lengua y la cultura que genera cada sociedad ${ }^{13}$. Por otro lado, esta riqueza textil demuestra la existencia de especialistas -tejedores- dentro de la población de agricultores, lo que da cuenta de una organización más compleja en términos de roles y funciones de algunos miembros de la población de la Cultura Arica.

\section{La PResencia de los Reinos altiplanos Circuntiticaca en la sierra de Arica}

Los datos arqueológicos señalan que aproximadamente a partir del 1200 d.C., diversos grupos humanos provenientes del altiplano comenzaron a ocupar enclaves ecológicos en las cabeceras de valles de la vertiente occidental del Pacífico. Siendo un espacio ocupado por agricultores serranos dependiente de la Cultura Arica ${ }^{14}$. Algunos antecedentes a considerar para comprender este proceso son:

a) Quinientos años antes, Tiwanaku habría ocupado la vertiente del Pacífico en búsqueda de tierras aptas para la agricultura, por lo tanto, conocían el territorio y sus potencialidades.

b) A pesar de que Tiwanaku colapsó como Estado influyente en la vertiente occidental, grupos aimaras ligados a los reinos circuntiticaca que estuvieron dentro de la organización de Tiwanaku siguieron establecidos en estos valles occidentales.

c) Al constituirse como reinos, como el caso de Carangas, Pacajes y Lupacas, estos organizaron su economía en virtud de sus necesidades, motivo por el cual las tierras de la vertiente oriental y occidental andina siguieron siendo explotadas con fines agrícolas cultivando frutales, cereales y hortalizas y marítimos, recolección del guano, pescado deshidratado y mariscos.

La ocupación de la sierra por parte de las poblaciones altiplánicas habría sido un proceso gradual, no observándose una estrategia de conquista armada o militar, sino más bien se habría seguido un patrón de ocupación de enclaves a través de colonias o grupos de familias. Estos grupos altiplánicos habrían conservado sus tradiciones culturales ancestrales, adquiriendo una relación con el entorno natural y constituyendo lo que Shank y Tilley e Ingold entre otros ${ }^{15}$, han llamado "paisajes"16.

Algunos de estos grupos se asentaron en espacios ya habitados por las poblaciones de la Cultura Arica, no habiéndose encontrado señales de enfrentamientos ${ }^{17}$. Uno de

13 Avtar Brah, Cartographies of Diaspora: Contesting Identities. Gender, Racism, Ethnicity, London, Routledge, 1996.

14 Muñoz y Chacama, op. cit., 130-131.

15 Michael Shanks y Chris Tilley, Reconstructing Archaeology, Cambridge University Press, New York, 1987. Tim Ingold, The Perception of Environment Essays on Livelihood, Routledge, London and New York, Dwelling and Skill, 2000.

16 Jeyni González, "Paisaje e Identidad Yabarana en el contexto del proceso de demarcación territorial indígena venezolano", Revista venezolana de Economía y Ciencias Sociales 15:3, Caracas, 2009. Según González, el Paisaje es concebido como un sistema de significados creados por los agentes sociales a través de su acción cotidiana.

17 Muñoz y Chacama, op. cit., 182-184. 
los bienes más representativos de la influencia altiplánica fue la alfarería, representada esta por los estilos de engobes rojos con decoración en negro, con líneas geométricas y motivos zoomorfos. Esta cerámica ha sido definida, entre otros estilos, como Chilpe; otras no presentan decoración sino que solamente engobes rojos o un pulido sobre la pasta. Respecto a sus viviendas y arquitectura funeraria, estas fueron construidas de acuerdo con el patrón local, lo que demostraría la existencia de una estrategia orientada a la adopción del modelo regional, cuyo objetivo habría sido facilitar la integración con las poblaciones locales (Coles). Quizás algunas diferencias en torno a las habitaciones están dadas en su interior, donde las poblaciones altiplánicas habrían construido separaciones interiores, algunas con entradas con forma del signo coma ${ }^{18}$.

Estas poblaciones a diferencia de los grupos locales, establecieron sus centros administrativos en el altiplano, enviando colonos a los valles serranos y costeros a manera de archipiélagos ${ }^{19}$. Además, en su primer momento estuvieron organizados bajo un jefe que estableció contacto con los "yungas" de valles serranos aportando ideas que se materializaron en los trabajos agrícolas y ganaderos. Por ello, es probable, que estos grupos altiplánicos hayan recibido tierras agrícolas y espacios para asentarse en señal de reciprocidad. Sin embargo, en la medida que estas poblaciones se fueron asentando, paulatinamente y aumentando demográficamente, lograron establecer una serie de alianzas multiétnicas con las poblaciones locales, logrando finalmente poblar más densamente el espacio serrano ${ }^{20}$. Un vez establecido este poblamiento altiplánico dentro de un contexto de coexistencia e interacción, pareciera que un mayor control de los espacios agrícolas comenzó a ser manejado por las poblaciones venidas de la puna, lo cual condujo a sus jefes (caciques) a organizar con mayor frecuencia el manejo y control de la economía de la sierra y los valles costeros, posicionando sus ídolos y ancestros a través de sus "chullpas" construidas en los sectores colaterales de sus aldeas ${ }^{21}$. En este contexto, las propuestas de un tercer caso de verticalidad, estudiadas por Shimada y Dillehay ${ }^{22}$, distinguen una dinámica interacción entre grupos locales en la costa, valle, sierra y altiplano, teniendo por ejemplo, su epicentro el valle de Lluta ${ }^{23}$.

Las sociedades locales y altiplánicas, poseyeron diferencias simbólicas, que se expresaron en la materialidad cultural, ya sea textil y alfarera, como también en su iconografía e ideología. Dichas distinciones, dan cuenta de la convergencia de distintas

18 Iván Muñoz, Juan Chacama, Gustavo Espinosa y Luis Briones, "La ocupación prehispánica tardía en Zapahuira y su vinculación a la organización social y económica Inca”, Chungará 18, Arica, 1987, 67-90.

19 John Murra, El control vertical de un máximo de pisos ecológicos en la economía de las sociedades andinas, Huanuco, Universidad Nacional Hermilio Valdizán, 1972.

${ }^{20}$ Iván Muñoz, "Asentamientos e interrelaciones culturales: Un aproximación al proceso prehispánico tardío en la sierra de Arica", I. Farrington y R. Raffino (eds.), Tiwantinsuyu 2, 1996, 44-58.

${ }^{21}$ El ídolo es un artefacto mueble y mnemotécnico, que posee una representación simbólica y religiosa, además de una diversidad de expresiones estilísticas. Así, el ídolo cumple la función de reafirmar e intensificar el sentido de identidad entre los miembros de determinadas sociedades humanas, tal como ocurrió en los Andes prehispánicos. Por tanto, el concepto está asociado a las interpretaciones que construyeron los cronistas del siglo XVI.

22 Calogero Santoro et al., "Revisita al tercer caso de verticalidad de John Murra en las costas de los Andes centrales y centro sur", Chungará 42:1, Arica, 2010, 325-340.

${ }^{23}$ Ibid., 327. 
etnicidades en un espacio cultural como Arica $^{24}$, donde se expresaron además, distintos símbolos identitarios, fronteras culturales y grupos humanos que poseen interacciones socioculturales permanentes, tal como lo han planteado Philippe Poutignat y Jocelyne Streiff-Fernart ${ }^{25}$, al discutir la función de la etnicidad. Las evidencias sugieren que dichas relaciones y vinculaciones interétnicas tuvieron una fuente de sentido y acción colectiva, que estuvieron sujetas a transformaciones y subjetividades, permitiendo el surgimiento de significados, discursividades e identidades disímiles, no exentas a fracturas y tensiones al interior de las sociedades indígenas que ocuparon valles y quebradas ${ }^{26}$.

Este dominio según la documentación conocida para la primera parte del siglo $\mathrm{XVI}^{27}$, no solamente alcanzó el espacio serrano, sino que mantuvo colonias o enclaves en la costa ya que ofrecía una gran potencialidad de recursos productivos de necesidad en el altiplano, siendo en consecuencia un período de interacción social, cultural y económica ${ }^{28}$.

\section{LA OCUPACIÓN INCA EN LOS VALLES SERRANOS}

Una vez organizado el espacio serrano por las poblaciones vallunas de los valles bajos costeros y altiplánicas, en términos productivos, alrededor del 1440 d.C. se habría dado paso al inicio del período Inca en la zona, cuya impronta se observa en los elementos arquitectónicos, cerámicos y textiles. Curiosamente con su presencia se constata una disminución de los elementos iconográficos que caracterizaron a la Cultura Arica con sus clásicos estilos San Miguel, Pocoma y Gentilar. La estrategia de dominio empleada por el Tiwantinsuyo se estructuró a partir del dominio que hicieron de los reinos circunlacustre asentados en la cuenca del lago Titicaca quienes mantenían colonias en los valles costeros del Pacífico desde hacía 300 aproximadamente, por lo tanto, la propuesta de manejo y control se habría ejercido de manera indirecta, a través de las colonias o mitimaes asentadas en la vertiente occidental andina. Los incas contribuyeron con una serie de ideas, bienes y tecnologías arquitectónicas, mejorando entre otros los caminos y construyendo tambos donde además concentró la producción estatal.

En el caso de los valles altos de Arica, una de las primeras estrategias del Estado Inka, puestas al servicio de las comunidades serranas fue el mejoramiento de la red vial ubicada a la altura de los 3.000 m.s.n.m., la que fue ensanchada, empotrada en los sectores laterales y emplantilladas con piedras en las entradas y salidas de los

24 La etnicidad entendida como una serie de prácticas culturales y perspectivas que distinguen a una determinada comunidad de personas, donde los grupos étnicos se ven a sí mismos como culturalmente diferentes de otros grupos sociales y son percibidos de la misma manera por otras agrupaciones humanas.

25 Philippe Poutignat y Jocelyne Streiff-Fernart, "El ámbito de investigación de la etnicidad: cuestiones claves", Theories de l'Ethnicite, París, Presses Universitaires de France, 1995, 154-188.

26 Hans Gundermann, "Sociedades indígenas, municipio y etnicidad: La transformación de los espacios políticos locales andinos en Chile", Estudios Atacameños 25, 2003, 55-77.

27 Jorge Hidalgo, Historia andina en Chile, Santiago, Editorial Universitaria, 2004.

28 Virgilio Schiappacasse y Hans Niemeyer, "Avances y sugerencias para el conocimiento de la prehistoria tardía de la desembocadura del valle de Camarones, Chungará 22, Arica, 1989, 63-84. 
poblados como Zapahuira, Huaihuarani, Saxamar, Socoroma, etc. Asimismo, cimentaron y nivelaron en los sectores de mayor pendiente los senderos. Este camino conectó todos los poblados serranos constituyéndose en la columna vertebral sobre el cual giraron los asentamientos locales.

Desde el punto de vista arquitectónico los incas construyeron edificios tipo "tambos", estos se caracterizaron por una estructura edificada en forma rectangular, con piedras de doble muro, rellenados con material de grava en su interior. Algunas de estas construcciones presentan en sus paredes pequeños rectángulos (hornacinas) donde depositaron ídolos, otras fueron enlucidas utilizando una argamasa de barro. Estos tambos varían en el número de estructuras 7 a $10 \mathrm{~m}$; algunas fueron utilizadas como Collcas -depósitos- donde se habría depositado el excedente de la producción local que iba al Estado Inca ${ }^{29}$. En otros casos, tambos como Zapahuira y Incahullo habrían servido como albergue del representante del Inca, funcionario que estuvo a cargo de contabilizar y controlar la economía local. La presencia de estos tambos junto a la red vial, es un indicador de la concepción Inca de mantener buenos caminos junto a grandes almacenes o centros administrativos estatales ${ }^{30}$.

Otro elemento característico de la influencia Inca en la sierra de Arica fue la alfarería, está a diferencia de la cerámica hecha por la población local, fue mejor manufacturada y con formas especiales. Una de ellas lo constituye la forma de aríbalo, cerámica emblemática del Estado Inca que asemeja al grupo "Cuzco B" 31 , aunque no presentan una compleja iconografía como las que se hallan en la zona nuclear del imperio, sino que engobes rojos, con algunos trazados geométricos de color negro, lo que fue identificado como imitación "Cuzco B" 32 . Otros tipos de cerámica fueron las escudillas de engobe rojo con decoración de llamitas en su superficie interna. Este tipo de cerámica es característica de las poblaciones del área circunlacustre del Titicaca, siendo denominada por algunos autores como "Inca Pacajes" ${ }^{33}$, Saxamar $^{34}$ o estilo "Inca Altiplánico Circunlacustre" ${ }^{35}$. Ambos estilos cerámicos -aríbalos y escudillas-, se hallan frecuentemente en los recintos administrativos ligados con el poder y en entierros excepcionales con ofrendas novedosas. Sin embargo, al margen de estas novedosas tecnologías relacionadas con la cerámica y arquitectura, no existieron transformaciones en otros aspectos de la cultura así por ejemplo se mantuvo los modelos tradicionales en la forma de construir sus viviendas y enterrar a sus muertos.

El universo espacial de carácter productivo que proporcionaron los valles costeros y serranos del extremo norte de Chile al Inca fue de mucho interés desde la

29 Chacama y Muñoz, op. cit., 215, 217, 218 y 219.

30 Iván Muñoz, Juan Chacama y Gustavo Espinosa, "El poblamiento prehispánico tardío en el valle de Codpa. Una aproximación a la historia regional”, Chungará 19, Arica, 1987, 7-70.

31 John Rowe, "An introduction to the Archaeology of Cuzco", Papers of the Peabody Mus. of Am. Archaeology and Ethnology XXVII:2, 1944, 183-203.

32 Schiappacasse y Niemeyer, op. cit., 76-77.

33 Stig Ryden, Archaeological Research in the Highlands of Bolivia, Götemborg, Elanders Boktryckeri Aktiebolog, 1947.

34 Percy Dauelsberg, "Contribución a la arqueología del valle de Azapa”, L. Álvarez (ed.), Museo Regional de Arica (Reedición de Boletines del 1 al 7), Arica, Universidad de Tarapacá, 1995, 36-52.

35 Schiappacasse y Niemeyer, op. cit., 76. 
perspectiva etnogeográfica, en el contexto de la ocupación y uso de estas cuencas hidrográficas, lo cual permitió una selectividad de la producción agrícola tanto de los valles de agua dulce como salados ${ }^{36}$. Junto a estos valles la costa constituyó otro medio favorable para los intereses del Estado Inca, la explotación tanto de la pesca como de la recolección de productos marinos les permitió contar con recursos permanentes para el mantenimiento de las poblaciones altiplánicas. Por otro lado, también tuvo importancia la explotación del guano de aves extraído de las covaderas del litoral, recurso utilizado como fertilizante para abonar las tierras agrícolas.

El interés por la explotación de los recursos agromarítimos permitió una amplia movilidad poblacional que complementó el sistema de horizontalidad con la verticalidad económica ${ }^{37}$. Un aspecto interesante de estas poblaciones es que a pesar de convivir o coexistir en un mismo territorio, muchos de ellos fueron originarios de distintas regiones o valles, lo cual refleja el sentido de identidad y multietnicidad que tuvo en el siglo XVI la costa y valles serranos de Arica $^{38}$.

Esta apretada síntesis, sobre interacción y cambio presentada para los períodos prehispánicos en los valles altos o sierra de Arica, nos hace reflexionar en torno a la forma que se pudo estructurar el tejido social, partiendo de la base que los responsables de agriculturizar dichos valles fueron las poblaciones locales de origen costero, caracterizadas por los grupos San Miguel, Pocoma y Gentilar; quienes poseían una larga experiencia de cultivos y uso de sistemas agrícolas en los valles bajos de Ari$\mathrm{ca}^{39}$. Sin embargo, para alcanzar este desarrollo agrícola debieron modelar el territorio agreste que caracterizan las quebradas de la precordillera de Arica, construyendo terrazas y canales por sectores de difícil acceso. A esta compleja y armónica arquitectura agrícola se suma la construcción de senderos, red vial que integró los distintos poblados a lo largo de estas sinuosas y profundas quebradas.

Con el arribo de las poblaciones altiplánicas postiwanaku estas habrían ampliado mayores áreas cultivables aprovechando la experiencia de las poblaciones locales, situación que habría sido aprovechada igualmente por los Incas, haciendo un mejoramiento de la red vial central que cruza la sierra de Arica a la altura de los $3.000 \mathrm{msnm}$.

\section{Los CAmbios sociales y culturales en los valles altos de Arica DURANTE la CONQUISTA HISPANA}

Desde el punto de vista arqueológico no observamos grandes cambios culturales en los valles altos de Arica, en lo que respecta a los primeros períodos de la influen-

\footnotetext{
${ }^{36}$ Luis Álvarez, "Etnopercepción andina del espacio, valles dulces y valles salados, en la vertiente occidental de los Andes", Diálogo Andino 10, Arica, 1991, 9-20.

37 María Rostworowski, "Mercaderes de valle de Chincha en la época prehispánica: Un documento y unos comentarios", Revista Española de Antropología Americana T.5, Madrid, 1970, 135-178.

38 Efraín Trelles, Lucas Martínez Vegazo: Funcionamiento de una encomienda peruana inicial, Lima, Editorial PUCP, 1991.

39 Jorge Hidalgo y Guillermo Focacci, "Multietnicidad en Arica, Siglo XVI, evidencias etnohistóricas y arqueológicas”, Chungará 16-17, Arica, 1986, 137-148.
} 
cia hispana. El axioma de cambio cultural, que se plantea se remite a la idea simmeliana de la correspondencia entre "cultura y cambio" 40 , es decir, cuando mayor es el cambio en un determinado lugar, mayor también es la necesidad de sustitución de los sistemas de creencias religiosas, rituales y culturales frente al cambio ideológico, y que no deja de ser contante. Estos principios, están relacionados con las ideas de difusión y aculturación propuestas por Malinowski y Vinatea para explicar el cambio cultural $^{41}$, ya que permiten comprender cómo los diversos grupos humanos generan préstamos de los rasgos culturales mediante el intercambio cultural y económico, o como consecuencia de la interacción de un grupo dominante/dominado ${ }^{42}$.

Las evidencias halladas más bien nos hablan de una continuidad de objetos y bienes en cuanto a la forma y tecnología vinculados a período prehispánicos. Uno de los registros arqueológicos más temprano datados corresponde a 1580 d.C., en el tambo de Cerro Blanco, valle de Codpa, en él observamos la presencia de herraduras, clavos, cerámica vidriada, asociada a la cerámica indígena local, constituyendo uno de los testimonios más tempranos de la presencia europea en las cabeceras de valles.

Sin embargo, las fuentes etnohistóricas en el mismo período nos describen aspectos sobre la composición étnica de la población de los valles bajos y altos de Arica, la que habría estado integrada por "pescadores" y "agricultores" yungas, constituyendo un grupo étnico que compartió el mismo legado cultural y concepciones ideológicas, poseyendo además una estructura organizacional dual compartida y complementaria que subsistió hasta inicios del siglo XVII ${ }^{43}$. Sin embargo, las fuentes documentales y los datos arqueológicos sostienen que estas sociedades poseyeron una autosuficiencia económica y política desde el período Intermedio Tardío, siendo más tarde integradas a las áreas de influencias de los reinos altiplánicos e incas, cuya estrategia de dominio involucró la movilización en estos valles de una serie de colonias o "mittani" ${ }^{44}$, constituyéndose en enclaves productivos de carácter "estacionales o permanentes" $"$. Sin embargo, dichos cambios políticos, no evitaron la continuidad de la tradición e identidad costera, que a lo largo del siglo XVI, dejó por evidencia ajuares funerarios y textiles diferenciados de la tradición altiplánica para Arica ${ }^{46}$.

La existencia de una complementariedad económica horizontal, a nivel local y regional al interior de la población yunga, y más tarde con la ejecución de la reciprocidad asimétrica con los señores de altiplano, le permitieron una vigencia social y política que se extendió a lo largo del siglo XVI, ello a pesar de la instalación de la encomienda de indios, la creación del corregimiento de Arica y las reducciones de

40 Georg Simmel, Cuestiones fundamentales de sociología, Barcelona, Gedisa, 2000.

${ }^{41}$ Bronislaw Malinowski, The Dynamics of Culture Change: An inquiri into race relations in Africa, P. Kamberry (comp.), New Haven, Yale UniversityPress, 1945.

42 Eduardo Vinatea, Lecciones de Antropología social y cultural, Madrid, Editorial Dykinson, 2008.

43 Iván Muñoz, "Perfil de la organización económica social en la desembocadura del río Camarones. Período Intermedio Tardío e Inca”, Chungará 22, Arica, 1989, 85-112.

44 Concepto aimara que equivale a término colonial de "mitimaes".

45 Murra, op. cit., 191.

46 Liliana Ulloa, "Evolución de la industria textil prehispánica en la zona de Arica", Chungará 8, Arica, 1981, 97-108. 
pueblos de indios ${ }^{47}$. En este contexto, cabe señalar la siguiente interrogante, ¿cuáles son las filiaciones culturales y sociales de las poblaciones indígenas de los yungas occidentales a mediados del siglo XVI? La incorporación del territorio al dominio español, se inició tempranamente con el paso de los capitanes Rui Díaz y Juan de Saavedra, más tarde se instalaron en la región, Pedro Pizarro y Lucas Martínez de Vegazo, quienes se convirtieron en los prósperos encomenderos de los valles y altos de Arica $^{48}$. Los antecedentes aportados por Cook y Trelles, han establecido que hacia 1540, la encomienda de Martínez de Vegazo, incluyó a 1.887 indios tributarios que se distribuyeron entre Ilo, Azapa, Lluta y Tarapacá, además de algunos colonos localizados en Arequipa, agrupando una población total de 9.730 personas $^{49}$. Diversos autores han sostenido que el sistema de encomiendas no hizo distinción entre la población local y los colonos del altiplano, puesto que para la década de 1540 no hubo tasas de tributo ni ordenanzas que reglamentaran el trabajo indígena ni mucho menos la identificación de su filiación étnica.

En este contexto, Lucas Martínez recibió una encomienda integrada por una población yunga y por colonos del altiplano (Lupacas, Pacajes y Carangas), estos últimos siguieron manteniendo una dependencia económica y política con sus comunidades de origen ${ }^{50}$. No obstante, no existe claridad sobre la proporcionalidad de esta población de residencia temporal o permanente, que según Garci Diez de San Miguel para el caso Lupaca en 1567, alcanzaba cerca del millar de indios en condición de "mittani" en los yungas occidentales ${ }^{51}$.

La expresión de la multietnicidad en la región, tiene como característica principal, las sucesivas y simultáneas ocupaciones culturales y económicas de los diversos espacios ecológicos, tanto de la población yunga como la forastera ${ }^{52}$. Además, a partir de mediados del siglo XVI, la elite indígena comenzó a utilizar los instrumentos jurídicos hispanos disponibles con la finalidad de evadir la pesada carga tributaria impuesta por los encomenderos. Asimismo, se produjeron ácidas discusiones entre los propios encomenderos por el control de los indios tributarios y los mittani, de lo cual no se eximieron Lucas Martínez de Vegazo ni Pedro Pizarro, puesto que se

47 Trelles, op. cit., 203-204.

48 Noble Cook, Tasa de la Visita General de Francisco Toledo, Lima, UNMSM, 1975.

49 Coincidiendo con Noble Cook, Efraín Trelles considera que el número de indios tributarios hacia 1540 debió ser porcentualmente mayor al estimado en los estudios de Larraín. Véase Horacio Larraín, "Demografía y asentamientos de los pescadores costeros del sur peruano y norte chileno, según informes del cronista Antonio Vásquez de Espinoza (1617-1618)", Revista Norte Grande No 1, Santiago, 1974; Alejandro Málaga, Catálogo general del Archivo Municipal de Arequipa, Arequipa, Editorial Sol, 1974.

${ }_{50}$ Carlos Choque, Memoria y olvido del pueblo de Socoroma. Deconstruyendo su historia e identidad, Arica, Tierra Viva, 2009.

${ }_{51}$ La visita general realizada por fray Pedro Gutiérrez Flores logró identificar, en 1572, un número de 676 mitimaes entre Sama, Locumba y Moquegua, a la vez que precisó la existencia de indios que hablaban el idioma "coli" o "cole", que producían algodón, maíz y ají, además de complementar su economía con las actividades pesqueras. Véase Cañedo-Arguelles, op. cit., XIV-XV.

52 Alan Durston y Jorge Hidalgo, "La presencia andina en los valles de Arica, siglos XVI-XVIII. Casos de regeneración colonial de estructuras archipielágicas”, Chungará 29:2, Arica, 1997, 249-273. 
enfrentaron judicialmente por el control de los indios carangas asentados en Codpa ${ }^{53}$. Este hecho nos indica también que las encomiendas se presentaron de manera discontinua en el espacio andino, facilitando a cada encomendero un "mosaico étnico", que en el caso de Lucas Martínez se componía de mittani e indios naturales asentados en Arequipa, Ilo, Arica, Lluta, Azapa, Carumas y Tarapacá.

A partir de la implantación de la economía colonial asociada a la Villa Real de Potosí, se introdujeron cambios importantes en la región, hecho que se tradujo en la modificación de la producción textil local de manera gradual, puesto que los textiles y otros bienes fueron considerados como parte de los productos que se integraron a la "tasa del tributo" 54 . Paralelamente la alfarería local se integró a la demanda del mercado colonial, perdiendo su esteticidad e iconografía pues solo vino a cumplir un rol funcional al ser utilizados para las necesidades de transporte de bienes productivos como los cereales, vinos y aceites. Respecto al tema, Sempat Assadourian ${ }^{55}$, sostuvo que fue la organización económica del sistema colonial la que jugó un rol trascendente en los cambios sociales de las comunidades andinas, ya que ellas, orientaron su producción y tecnología para satisfacer la demanda de los centros urbanos y mineros que emergieron en la década de 1540. El producto de tales dinámicas fue la generación de interacciones y cambios culturales disímiles, ya que estos no se expresaron de manera idéntica en otras regiones andinas, ni tuvieron las mismas complejidades que la zona de Arica y Tacna, pues dicha población indígena, no solamente fueron participes del traslado de azogue y plata, sino también de cultura y tecnología hispana.

Por ello, los primeros asentamientos españoles no se limitaron solo al puerto de Arica, Tacna o la Quiaca, sino que buscaron territorios más cálidos como los cursos medios de los valles (i.e. Codpa en el valle de Codpa y, Humagata en el valle de Azapa), compartiendo los mismos espacios productivos con los agricultores indígenas. Posteriormente, hacia 1570, el virrey Francisco de Toledo dictó un conjunto de leyes que va a cambiar radicalmente la vida de los indígenas ${ }^{56}$. El reordenamiento territorial impulsado por el virrey Toledo buscó dar un mayor impulso al control de la población indígena a partir del tributo y de la organización de levas de "mitayos" que trabajarían en las minas de plata y mercurio del virreinato ${ }^{57}$. Esta política colonial generó además profundas repercusiones en la población indígena, pues se alteraron

53 Trelles, op. cit., 175-176. Helena Horta, "El gorro troncocónico o chucu y la presencia de población altiplánica en el norte de Chile durante el período Tardío (ca. 1470-1536 d.C.)”, Chungará 43: Número Especial 1, Arica, 2011, 551-580.

${ }_{54}$ El resultado de la tasa de 1550 para los indios de Arica impuso el pago de 60 piezas de ropa y para el año 1565 la cantidad de ropa tributable era de 192 piezas. Trelles, op. cit., 198-200.

${ }_{55}$ Carlos Sempat Assadourian, Sistema de la economía colonial. El Mercado interno, regiones y espacio económico, Lima, IEP, 1982.

${ }^{56}$ La política colonial de reducción de pueblos de indios identificó diferencias específicas y por lo cual estableció una serie de categorías de reducciones: "Pueblos de indios aledaños a ciudades, pueblos de indios aislados emergentes, capilla o poza de indios germen de un nuevo pueblo y finalmente la mutación de pueblos de indios a villas y ciudades con diversa fortuna; con una amplia serie de combinaciones". Hugo Unzaga, "Pueblos de indios durante la colonia", Revista del Museo Nacional de Etnografía y Folklore I, La Paz, 2010, 191.

57 Rodrigo Ruz, Alberto Díaz y Rodrigo Fuentes, Timalchaca. Fiesta, tradición y costumbre en el santuario de la Virgen de los Remedios, Arica, CONADI, 2011. 
las relaciones de parentesco, los circuitos económicos precedentes y el conjunto de elementos de la vida social y cultural existente ${ }^{58}$. Esta política de reducciones fue quizás una de las más combatidas por parte de los indígenas, y no solo por el hecho en sí de cambiar una ancestral forma de percibir y habitar el territorio, sino además porque les apartaba de sus huacas y ancestros, los alejaba físicamente de sus raíces simbólicas, sin las cuales les era casi imposible concebir la vida ${ }^{59}$. Esta reticencia constante a ocupar los espacios reduccionales, se reflejó en la inquietud que causa este hecho en la Iglesia, ya que durante las visitas eclesiásticas dirigidas a los indígenas se indagaba si estos obedecen la prohibición de volver a sus pueblos viejos ${ }^{60}$.

Arica no escapó a esta situación, la visita general de Juan Maldonado de Buendía por instrucciones de Toledo se inició con posterioridad a 1570. En ella se encontraron 226 pueblos en la región del "Colesuyo" los que fueron reducidos a 22, estableciéndose además trece doctrinas para administrar los sacramentos, siendo Poconchile en el valle de Lluta una de las primeras en crearse ${ }^{61}$. En el año 1618 fecha en que el "carmelita descalzo" Vázquez de Espinoza, recorrió el territorio, las reducciones ya están afianzadas, según su propio testimonio los pueblos están ya constituidos en su mayoría por un patrón de damero, cuyas calles en forma de una rejilla ortogonal y con la presencia de un templo cristiano, constituyen el símbolo más conspicuo de los "pueblos de indios"62. La espacialidad circundante de este nuevo orden es también diferente; los pueblos de reducción se constituyen en las cabeceras de los valles precordilleranos, buscando, de acorde al paradigma hispano, espacios más abiertos y planos, donde las quebradas aún no se tornan tan profundas, situación que les permite instalar los pueblos ortogonales en damero y por otro lado, responden a la premisa de ser espacios más abiertos, sin escondrijos donde esconderse del Señor. Así el patrón hispano que cubre los Andes con un nuevo orden de cosas, cambiando de modo significativo la forma de vida de las poblaciones andinas, si bien la economía agrícola sigue siendo en gran medida la misma de siempre, la conceptualización ideológica del espacio cultural y religioso cambió significativamente.

El producto del sistema de reducciones de pueblos de indios, fue la construcción ideológica del "indio" 63 , hecho que no consideró el mosaico étnico existente en la

58 Manuel Burga, Historia de América Andina, Quito, Edición de la Universidad Andina Simón Bolívar, 1999

59 Si bien la población indígena vivía en poblamientos dispersos. Esta forma de vida se redoblo en los primeros años de "encuentro", como un medio de defensa natural, debido al proceso de agresión que significó la conquista hispana.

${ }^{60}$ Alberto Díaz y Juan Chacama, "Procesos de idolatría, discursos nativos y religiosidad en el mundo andino colonial", Taller de Letras 51, Santiago, 2012, 53-74.

${ }^{61}$ Con posterioridad al proceso toledano, los pueblos andinos, organizados en el esquema hispano continuaron desplazándose o cambiando sus asentamientos por diversas causas internas y externas. Hidalgo, Historia andina ..., op. cit., 493, 2004.

${ }_{62}$ Alan Durston, "El proceso reduccional en el sur andino: confrontación y síntesis de sistemas espaciales", Revista Historia Indigena 4, Santiago, 2000, 75-102.

${ }^{63}$ Guillermo Bonfil consideró que tales construcciones generalizantes eran compartidas por todos los sectores del mundo hispano-criollo, ejemplificando con los testimonios que revelan la mentalidad de los misioneros: para ellos los indios eran infieles, gentiles, idólatras y herejes. Véase Guillermo Bonfil, "El concepto de indio en América: Una categoría de la situación colonial”, Anales de la Antropología Vol. 9, 
costa, valles y sierra de Arica, ni mucho menos consideró las profundas diferencias culturales y políticas que existieron en grupos humanos tan heterogéneos.

\section{DECONSTRUCCIÓN Y TRANSFORMACIÓN POLÍTICA DEL ESPACIO SERRANO EN LOS SIGLOS XVI Y XVII}

En la segunda mitad del siglo XVI, se aceleraron los cambios políticos y sociales en el territorio, no obstante a estas trasformaciones, la vida cotidiana y cultural de la población indígena siguió expresándose bajo los mismos principios y valores del período anterior. El impacto de la política colonial y el sistema de explotación económica que se aplicó a la población indígena con el sistema de encomienda, vino a generar un descenso demográfico de un $36 \%$ entre 1540 y $1570^{64}$. En términos estadísticos la disminución de la población fue de $-3,8 \%$ en la costa y de $-1.1 \%$ en la sierra, hecho que aceleró además el despojo de tierras que estaban viviendo los indios de la costa de Arica ${ }^{65}$, situación que ocurrió en momentos en que el territorio era reorganizado a partir de la creación del Corregimiento de Arica ${ }^{66}$. Este hecho no pasó desapercibido para la población indígena "yunga" ${ }^{67}$, que generó un proceso de rearticulación política a partir de sus viejas estructuras organizativas locales y donde además, se expresó una ruptura con el sistema de reciprocidad asimétrica que los supeditaba a los señores étnicos del altiplano, ello considerando la hipótesis de una sujeción política de los yungas respecto a los antiguos reinos altiplánicos ${ }^{68}$.

A mediados del siglo XVI, surgió una serie de pleitos judiciales entre los encomenderos de la región por el control de los indios tributarios existentes en la costa y sierra de Arica, este hecho fue aprovechado por los indios principales del Corregimiento de Carangas liderados por Martin Chuquichambi ${ }^{69}$, para reclamar por la devolución de los "mittani" carangas en 1549 , ya que estos indios estaban en rebeldía y se resistieron a volver a los ayllus altiplánicos. La iniciativa de los jefes étnicos Carangas se sustentó en los reclamos que hicieron los Lupacas de Chucuito por la

México D.F., 1972, 104-124. Por otro lado, Estenssoro nos informa que estas fronteras étnicas fueron legitimadas por la iglesia católica de la época. Juan Carlos Estenssoro, "El simio de Dios: Los indígenas y la Iglesia frente a la evangelización del Perú, siglos XVI-XVII", Bulletin de l'Institutfrancaisd'EtudesAndin es 30:3, Lima, 2001, 455-474.

${ }^{64}$ Este descenso demográfico además fue generado por las huidas y enfermedades que afectaron principalmente a los indios en condiciones de tributar, hecho que llevo a Trelles a afirmar que la expectativa de vida era muy baja. Los efectos de los cambios demográficos fueron más evidentes en la costa sur del Perú colonial, pues a la existencia de las enfermedades se le sumaron los terremotos y prolongadas sequías que terminaron generando una elevada tasa de despoblación indígena. Véase, Noble Cook, La catástrofe demográfica andina. Perú 1520-1620, Lima, PUCP, 2010.

65 Juan Herrera, El amanecer de Arica y Tarapacá en el siglo XVI-XVIII, Iquique, IECA, 1997.

${ }_{66}$ Trelles, op. cit., 152-158.

${ }^{67}$ Luis K. Watanabe, Michel E. Moseley y Fernando Cabieses, "Trabajos Arqueológicos en Moquegua”, Programa Contisuyo del Museo Peruano de Ciencias de la Salud 3, Lima, 1990.

${ }^{68}$ Choque y Pizarro, op. cit., 260-261.

69 AGI, Justicia, $N^{\circ} 658$, f.590. 
devolución de sus 144 mittani tributarios localizados en Azapa y Lluta ${ }^{70}$. El reclamo de Chuquichambe ${ }^{71}$, no fue exitoso y en el mes de enero de 1612, el cura párroco Fernando de Altamirano ${ }^{72}$ realizó nuevas alegaciones solicitando a la Real Audiencia de Charcas su intervención para la devolución de los indios huidos, radicados en los altos de Arica.

Según se desprende de las declaraciones de Juan Polo de Ondegardo (1560) ${ }^{73}$, los indios fugados se dirigían preferentemente a la costa a la jurisdicción del Corregimiento de Arica, donde habitaban antiguos colonos que no deseaban volver a sus tierras de origen por temor al servicio personal y a los trabajos de mitayos en Potosí. Esta situación permitió que los indios huidos engrosaran el número de tributarios yungas, que estaban exentos de la mit'a de Potosí, contando para ello con el beneplácito de las autoridades coloniales del Corregimiento de Arica, "quienes así obtenían mano de obra en una época de rápida despoblación"74. El proceso de rearticulación y de construcción de las estructuras sociales, territoriales y políticas de los indios yungas y antiguos colonos, implicaron una redefinición de la territorialidad sagrada, como también de la reinterpretación del mundo sagrado y simbólico, es decir, se generó una nueva jerarquización de los cerros y huacas en el espacio yunga, evitando así una perpetuación de las relaciones de reciprocidad asimétrica con el espacio Caranga, constituyéndose así, la sierra de Arica en una espacio de articulación o taypi ${ }^{75}$.

Este proceso se vio reforzado con la creación de los pueblos de indios, pues se generó una base de poder y legitimidad que obligó a los señores étnicos a integrar la población local y con los mittani, reeditando las viejas prácticas de reciprocidad asimétrica, pero a una escala local ${ }^{76}$. Así, los indios principales de Arica en el año 1581 unificaron sus cacicazgos, que fue integrado por las autoridades de Auzipar, Lluta, Huanta y Camanchacas, instalando como señor principal a "Juan Tauquió Tauquina, que se hacía reconocer como Cacique de Azapa, Chacalluta y Lluta"77. Si bien, los Carangas renovaron sus esfuerzos por recuperar sus antiguos colonos en el siglo XVIII, después de la crisis demográfica producida por la epidemia de 1715 a 1720, sin embargo, no tuvieron éxito, ya que el cacique Diego Cañipa, acabó con la autoridad política de los carangas definitivamente "dentro de este repartimiento de los Altos de Arica $^{78}$, y los colonos carangas fueron integrados al cacicazgo de Codpa" ${ }^{79}$.

70 Trelles, op. cit. 172-173.

71 "Memorial de los principales de Hatun Carangas", AGI, Charcas, № 49.

72 Carta $\mathrm{N}^{\circ}$ 2, AGI, Charcas, $\mathrm{N}^{\circ} 49$.

73 Polo de Ondegardo, Religión y Gobierno de los Incas, Imprenta y Librería Sanmarti, 1916.

74 Hidalgo ha sostenido que, si bien los indios del Corregimiento de Arica estuvieron exentos de la mit'a potosina, debieron acudir a variantes locales como la de Azapa o Tarapacá. Ver: Jorge Hidalgo, "La mit'a de Azapa 1680-1752: Un nuevo caso de mit'a local”, Diálogo Andino 7-8, Arica, 1989, 57-79.

75 Muñoz y Chacama, op. cit., 133.

76 Efraín Trelles consideró que los constantes cambios en la composición territorial de las encomiendas trajeron consigo permanentes readecuaciones en el uso y control de los espacios ecológicos, que los españoles supieron usar para incorporar un número mayor de tributarios.

77 Cavagnaro, op. cit., 330.

78 El Cacicazgo de Codpa es el sucesor del Cacicazgo de Lluta y Azapa en el siglo XVII.

79 María Gavira, Población indigena, sublevación y minería en Carangas (Bolivia), 1750-1804, Lima, Ediciones IFEA - UTA, 2008, 22. 
Esta unificación de cacicazgos no fue la única, pues en la medida que la población se dispersaba o disminuía, nuevamente se reorganizaba el espacio sacralizado y el territorio, impidiendo de esta manera que la elite Caranga pudiese recuperar a sus antiguos mittani, la cual termino fusionándose "armónicamente con la población yunga" ${ }^{80}$. En consecuencia, durante el período colonial, la sierra de Arica habría sido escenario de un proceso de regeneración de las estructuras políticas que venían desde tiempos prehispánicos, esto dentro del ideal de la eco-complementariedad y la disposición ecológica de recursos, lo que permitió la autonomía de los núcleos secundarios o locales que tuvieron como centros importantes a los pueblos de indios de $\mathrm{Pu}$ tre, Socoroma, Belén y Codpa, que gozaron de cierto grado de autonomía económica y política en los siglos XVII y XVIII ${ }^{81}$.

\section{COMENTARIOS FinALES}

Desde los períodos prehispánicos hasta el siglo XVII observamos dos grandes tradiciones culturales asentadas en los valles altos de Arica, a las cuales hemos denominado vallunas, conformada por grupos locales y de valles bajos, y altiplánica vinculadas a los reinos postiwanaku. El propósito de ambas tradiciones fue transformar en un vergel los valles precordilleranos, permitiendo que dichas cabeceras de valles, desde el punto de vista económico, se transformaran en espacios de articulación social y de intercambio de productos provenientes del litoral y de la puna. Este proceso al parecer no tuvo transformaciones profundas en la vida cotidiana y cultural de las poblaciones indígenas, sino hasta el siglo XVII, cuando por un lado se instaura el Sistema de Reducciones de pueblos de indios, donde no se consideraron las diferencias culturales que caracterizaban a los grupos humanos y por otro la aplicación del sistema de explotación económica denominada encomienda, donde la Corona española entregaba derechos a los colonizadores para obtener tributos sobre una porción de población indígena a cambio de protección y evangelización de estas mismas comunidades. Ambos sistemas permitieron un control económico, político, administrativo y eclesiástico de las poblaciones, desarticulando definitivamente la estructura social y económica de los pueblos indígenas, cuya organización aldeana giraba en torno al Ayllus, donde los conceptos como reciprocidad, redistribución y el manejo complementario de la economía fueron parte importante de las relaciones socioeconómicas.

Consideramos que para conocer los procesos históricos y sociales evidenciados entre los siglos X al XVII d.C. en los valles altos de Arica, es necesario remitirse a las antiguas poblaciones precolombinas conocidas arqueológicamente como Cultura Arica. Ahora bien, tomando como referencia las fuentes históricas del siglo XVI, la costa de Arica y sus valles más próximos se constituyeron como un escenario mul-

80 Rómulo Cuneo Vidal, Obras Completas, Lima, Edición Ignacio Prado, 1977.

81 Jorge Hidalgo, Nelson Castro y Soledad González, "La revisita de Codpa (Altos de Arica) de 1772 73 efectuada por el corregidor Demetrio Egan”, Chungará 36:1, Arica, 2004, 103-204. 
tiétnico, con habitantes que se definían como originarios de distintas latitudes, sin embargo, entre ellos desarrollaron fuertes lazos de parentesco e intercambio económicos, lo cual generó un poblamiento humano dinámico en un ambiente complejo como es el desierto de Atacama.

Al finalizar nuestro relato podemos señalar que a lo largo de este proceso cultural que cubrió aproximadamente 700 años, observamos dos hechos trascendentales en la vida de las comunidades de los valles altos de Arica. El primero dice relación con la conquista y transformación de los valles en tierras agrícolas, lo que produjo una ocupación humana permanente e interactuante con otros valles y áreas culturales circunvecinas; testimonios de esto son posibles de encontrar en la red de poblados ( $p u k a-$ ras) y caminos situados estratégicamente a lo largo de las cabeceras de valle, los que no habrían sufrido grandes transformaciones durante la influencia incaica y en los dos primeros siglos de la conquista europea. El segundo se refiere a las transformaciones económicas y sociales promovidas por el virrey Toledo, lo que provocó el quiebre y desarticulación de los agricultores de los altos de Arica y por ende el fin de una historia cuyo parámetro de vida giraba en torno a una propuesta precolombina.

Antes de terminar queremos dejar establecido que los límites de esta síntesis se establecieron en la medida que los autores evidenciaron cierta falta de información referida a investigaciones sobre arqueología histórica, estudios que en la medida que se realicen pueden aportar nuevas propuestas al conocimiento de las poblaciones de los valles precordilleranos del extremo norte de Chile.

FIG. 1

Esquema de interacción social entre grupos costeros y altiplánicos en las alturas de Arica, Siglo X al XVII d. C.

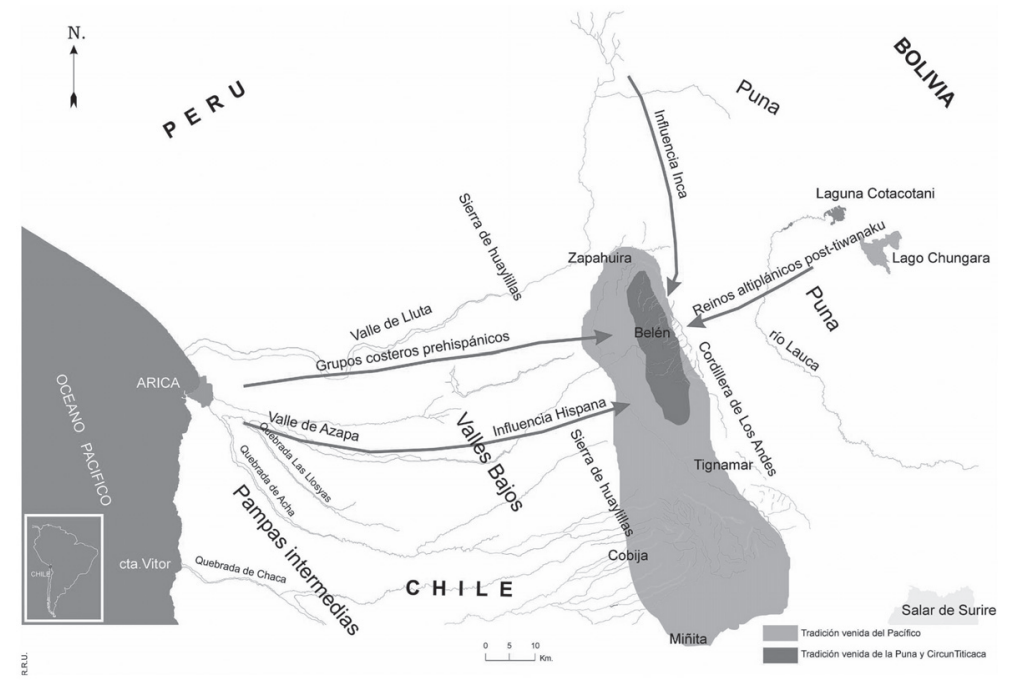


FIG. 2

Vista panorámica tomada del poblado preinca de Calacruz, sector de Socoroma

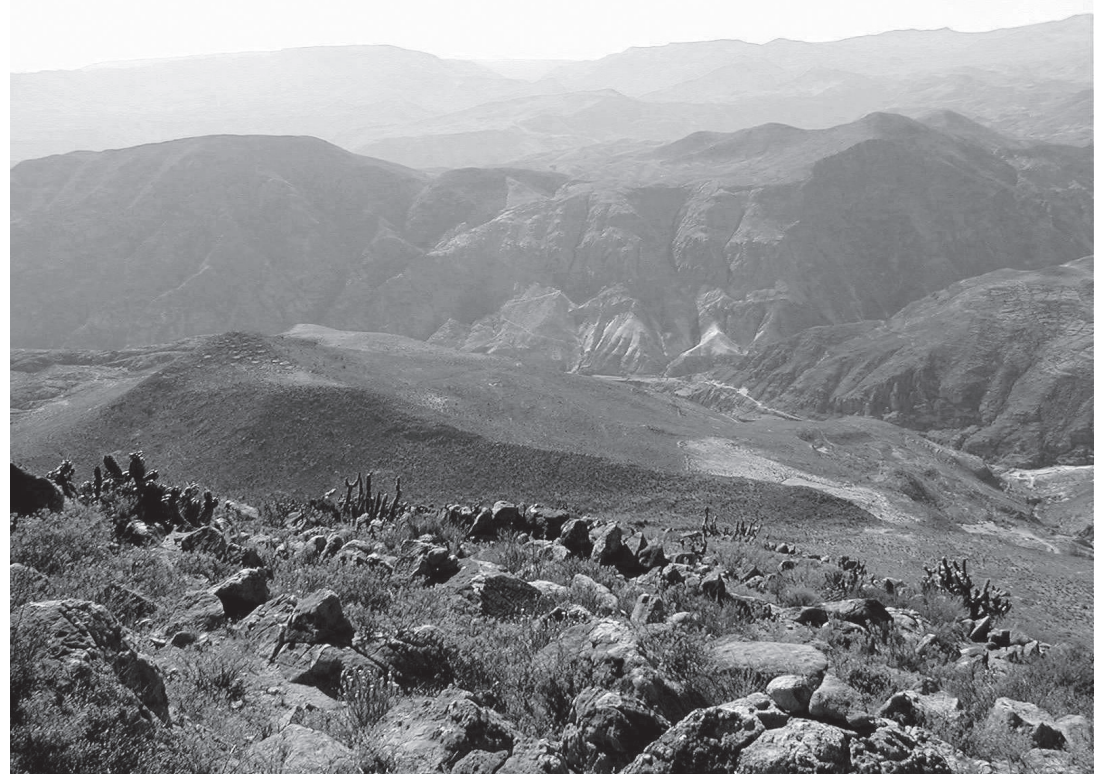

FIG. 3

Tambo Incaico de Zapahuira, al fondo cerro de Huaycuta ubicado en la pampa de Zapahuira, visible desde la ruta internacional Arica la Paz

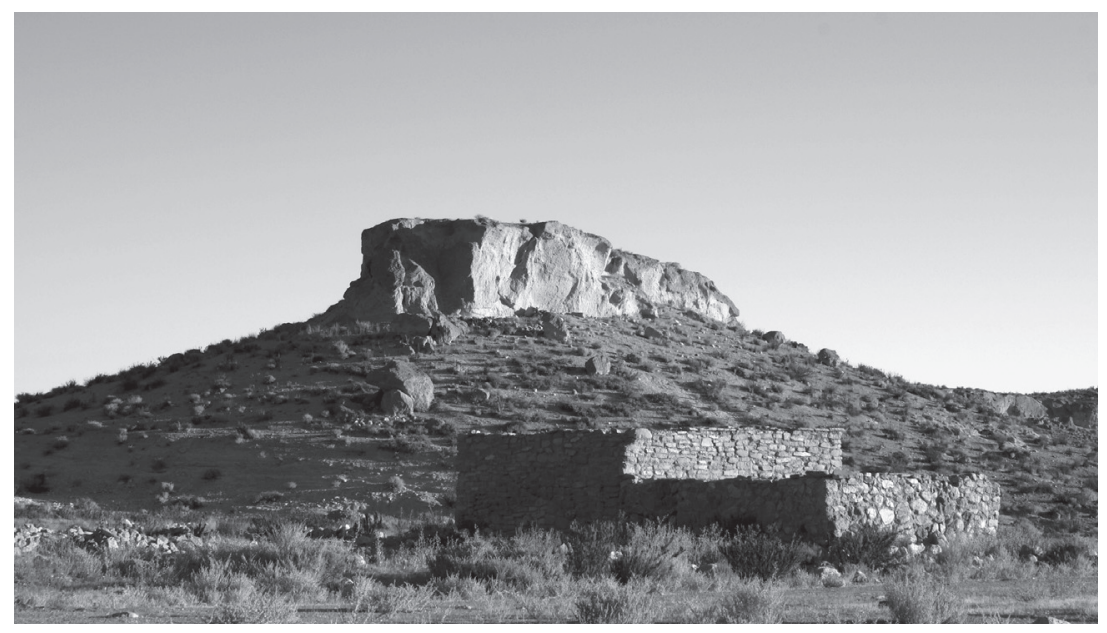


FIG. 4

Trazo del QhapaqNan o camino Inca, situado en las cercanías del pueblo Socoroma

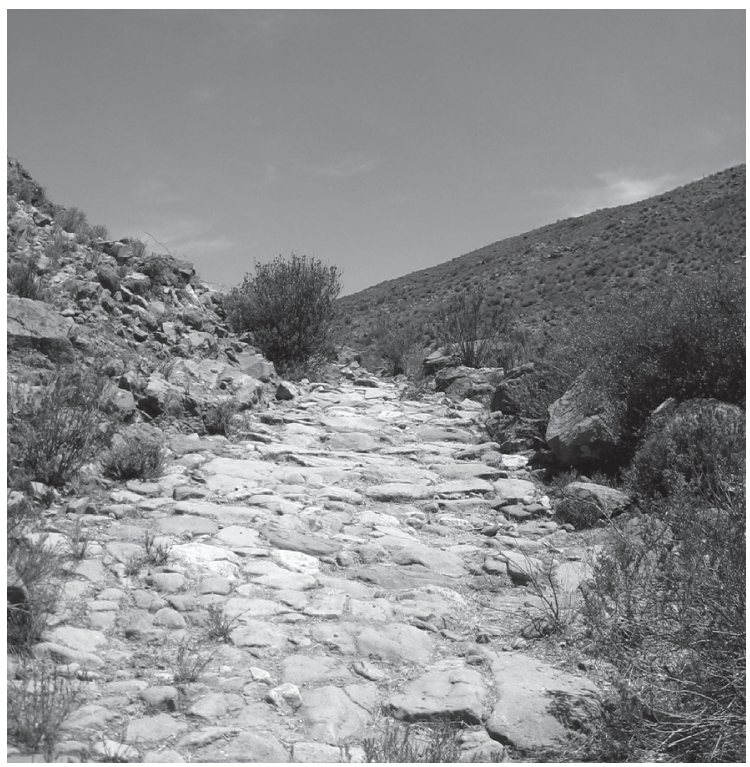

FIG. 5

Vista frontal de la iglesia del poblado de Belén (S. XVII)

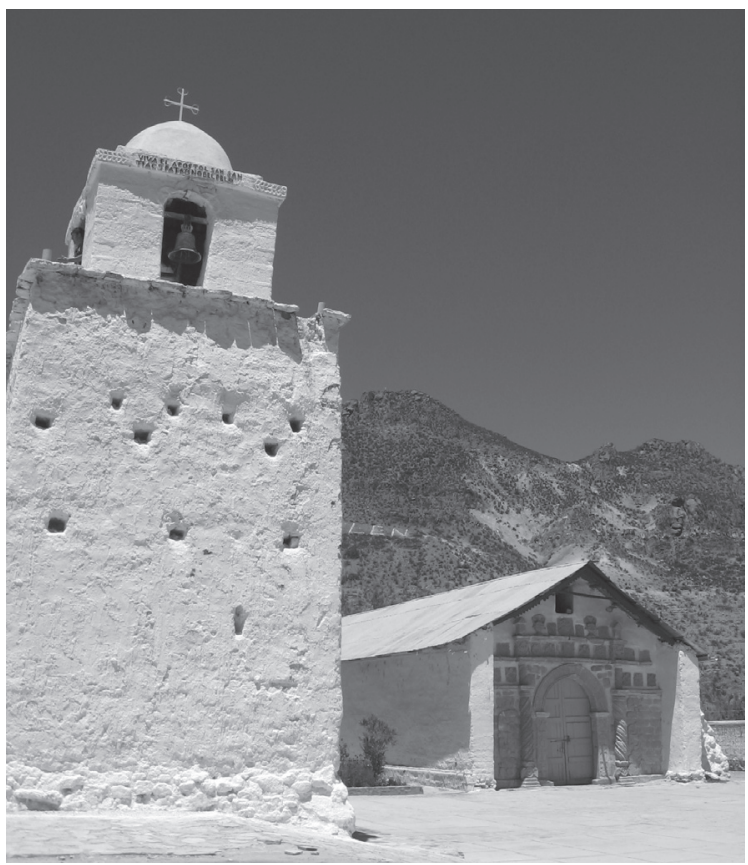


FIG. 6

Vista panorámica actual del poblado de Socoroma y su entorno geográfico

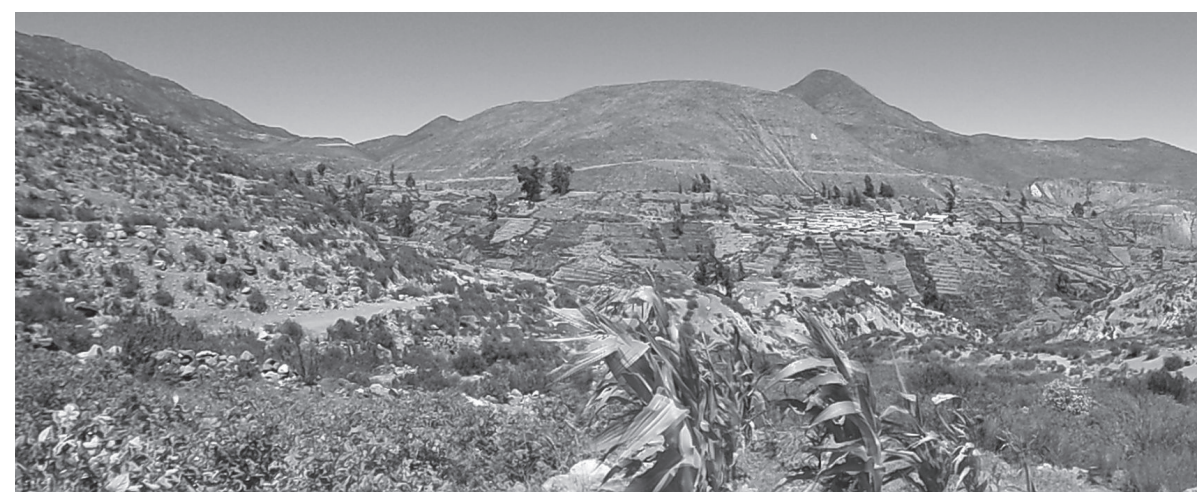

FIG. 7

Chulpa de Zapahuira, período Inca

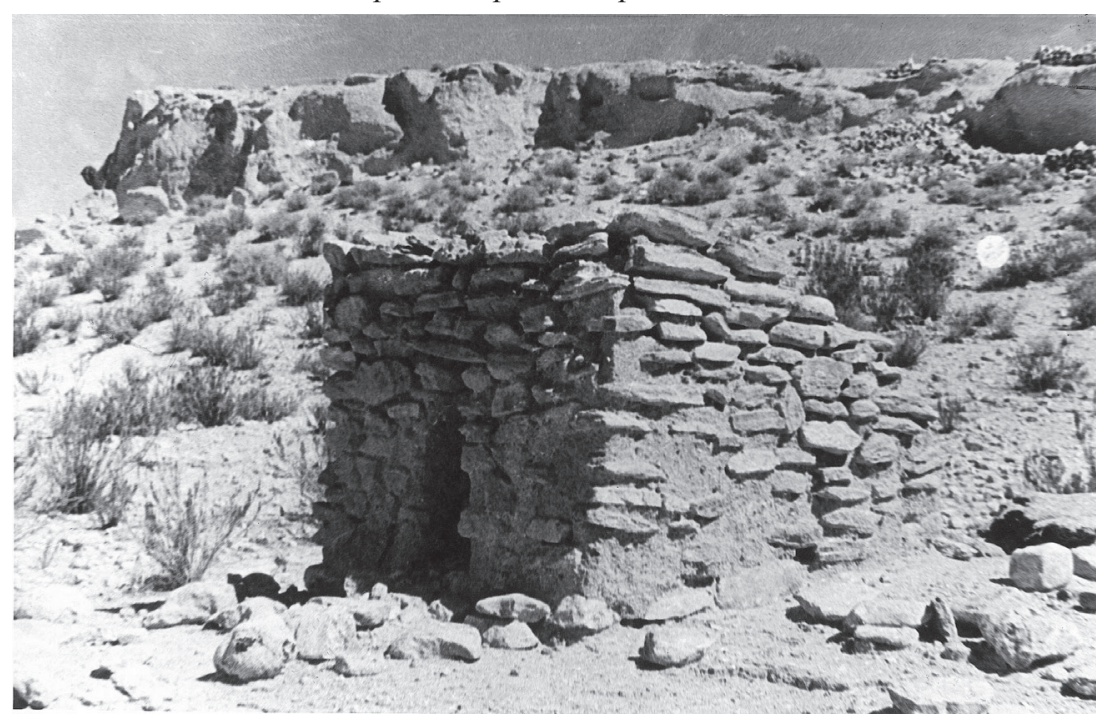


FIG. 8

Terrazas de cultivo sector de Belén

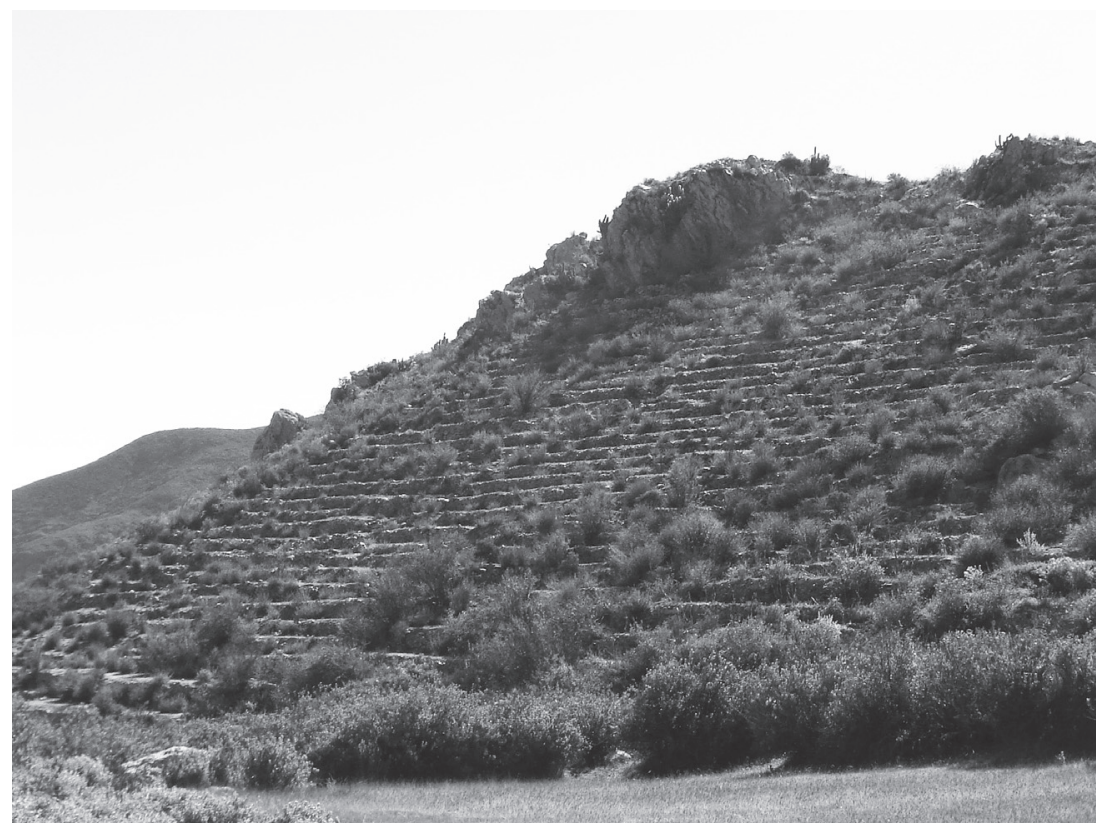

